\title{
Untargeted Metabolomic Profiles of Thai Herbal Sahatsatara Formula by Mass Spectrometry
}

\section{Natchaya Ziangchin}

Center of Applied Thai Traditional Medicine, Faculty of Medicine Siriraj Hospital, Mahidol University, Bangkok 10700

\section{Manmas Vannabhum}

Center of Applied Thai Traditional Medicine, Faculty of Medicine Siriraj Hospital, Mahidol University, Bangkok 10700

\section{Puthida Thepnorarat}

Center of Applied Thai Traditional Medicine, Faculty of Medicine Siriraj Hospital, Mahidol University, Bangkok 10700

Pravit Akarasereenont ( $\square$ pravit.auk@mahidol.edu )

Center of Applied Thai Traditional Medicine, Faculty of Medicine Siriraj Hospital, Mahidol University, Bangkok 10700

\section{Research Article}

Keywords: Sahatsatara formula (STF), Thai traditional medicine (TTM), Traditional Chinese medicine (TCMs)

Posted Date: July 8th, 2021

DOl: https://doi.org/10.21203/rs.3.rs-692225/v1

License: (c) (1) This work is licensed under a Creative Commons Attribution 4.0 International License. Read Full License 


\title{
Untargeted metabolomics profiles of Thai herbal Sahatsatara formula by mass spectrometry
}

\author{
Manmas Vannabhum ${ }^{1}$, Natchaya Ziangchin ${ }^{1}$, Puthida Thepnorarat ${ }^{1}$, Pravit Akarasereenont $* 1,2,3$ \\ ${ }^{1}$ Center of Applied Thai Traditional Medicine, Faculty of Medicine Siriraj Hospital, Mahidol University, \\ Bangkok 10700, Thailand \\ ${ }^{2}$ Department of Pharmacology, Faculty of Medicine Siriraj Hospital, Mahidol University, Bangkok 10700, \\ Thailand. \\ ${ }^{3}$ Siriraj Metabolomics and Phenomics Center, Faculty of Medicine Siriraj Hospital, Mahidol University, \\ Bangkok 10700, Thailand.
}

*Corresponding authors: Pravit Akarasereenont (pravit.auk@mahidol.edu)

\section{Abstract}

Thai herbal Sahatsatara formula (STF) has been used for more than three decades to relieve musculoskeletal pain, numbness and anti-flatulence in Thai traditional medicine (TTM). STF composed of 21 ingredients. Black pepper is the major constituent in this formula. Previous studies revealed that piperine was used for quality control assessment of STF. However, only one biomarker is not enough to assure quality determination of the poly-herbal medicine. In this work we established untargeted metabolomic profiling of STF using Liquid Chromatography-Mass Spectrometry (LC-MS) and identification compounds with Traditional Chinese medicine (TCMs) library in UNIFI software. STF was extracted three concentrations. The untargeted metabolomics profiles of STF were represented A total of 21 natural products were detected in in all STF extract concentrations both positive and negative ionization modes Additionally, there were discovered new chemical markers for quality control. Moreover, the method was simplifying and reproducibility.

\section{Introduction}

Thai traditional medicine (TTM) has been used for more than 800 years in Thailand. The theory of TTM are described that life composes of four major elements (earth, water, wind and fire), involving in physical and psychological well-being of human. Thus, the imbalance of the elements can enhance many diseases or illnesses in human. According to TTM knowledge, there are several treatments, contributing to pharmacological and non-pharmacological approaches such as massage, hot herbal compress, hot herbal steam bath and herbal medicine. Herbal medicines (HMs) commonly used for disease treatment and health promotion worldwide ${ }^{1,2}$. In TTM aspect, HMs are generally used for revitalizing status imbalance by prescribing various kinds of single herbs and formula ${ }^{3}$.

Thai herbal SAHATSATARA formula (STF) is the poly-herbal formula comprising of 21 ingredients composed of Piper nigrum L., Plumbago indica L., Piper retrofractum Vahl, Kleinhovia hospita L., Terminalia chebula Retz., Baliospermum solanifolium (Burm.) Suresh, Acorus calamus L., 1, 7, 7 trimethylbicyclo (2.2.1) heptan -2- one, Myristica fragrans Houtt. [Mace], Myristica fragrans Houtt. [Fruits], Lepidium sativum L., Anethum graveolens L., Ferula assa-foetida L., Pimpinella anisum L., Cuminum cyminum L., Merremia vitifolia (Burm.f.) Hallier.f., Nigella sativa L., Anacyclus pyrethrum (L.) 
Lag., Atractylodes lancea (Thunb.) DC., Picrorhiza kurroa Royle ex Benth., and Terminalia chebula Retz. Most of ingredients have various pharmacological activities (Supplementary Material, Table 1). STF has been traditionally used more than three decades by TTM practitioner and also widely applied to relieve musculoskeletal pain, numbness and anti-flatulence. It had been registered in the National List of Essential Medicines by the Ministry of Public Health since 2011. The main ingredient of the formula is pepper. There were many scientific evidences reported that piperine, alkaloid, was a major active compound of STF by using various techniques for quality control and herbal standardizations ${ }^{4}$.

Regarding to WHO traditional medicine strategy, quality control of HM purpose to ensure their consistency, safety and efficacy ${ }^{5}$. Because HM typically represents complexed molecules and there are more than 2,000 compounds in single herb, the difficulty of specific compound marker determination likewise plays an essential role in polyherbal formula ${ }^{6}$. There were previous studies of STF demonstrated the fingerprint patterns of standard piperine compare with piperine in STF using thin layer chromatography (TLC), quadrupole time-of-flight mass spectrometry (QTOF) ${ }^{4}$. Furthermore, piperine was used for a quantitative marker by using high performance thin layer liquid chromatography (HPTLC) and ultra-performance liquid chromatography (UPLC) approaches ${ }^{7}$. However, only one compound is not enough to claim the clinical efficacy and mechanism of action of STF.

Metabolomics or metabonomics is the new approach way for research to identify and quantify unique chemical fingerprint of small molecules $(<1,000 \mathrm{Da})$ that are involved in cellular reactions which is called metabolite profiles. There are perform two techniques approach including targeted and untargeted metabolomics; targeted is analysis of a specific set of metabolites, untargeted is analysis of all metabolite ${ }^{8-}$

${ }^{10}$. Nowadays, HMs quality control and herbal standardizations is challenging for the researcher in the world to establish good quality control assessment. Therefore, untargeted metabolomics becomes more interested and potential technique approach to discover possible new biomarkers and understanding biochemical change in plant metabolite ${ }^{11}$. Thus, this study aims to investigate metabolomics profiling of STF using Mass Spectrometry (MS) and database software by focusing on untargeted metabolomics analysis.

\section{Methods}

Chemicals and Reagents. The reference standards, including caffeine (3-Methyl-C13,99\%), piperine, sodium formate and sodium hydroxide, were purchased from Sigma - Aldrich (Missouri, USA). Cholic Acid-[2H4] was purchased from Isosciences and chemical company (Pennsylvania, USA). Ethanol (AR grade) and 2-Propanol (LC-MS grade) were purchased from Scharlau (Barcelona, Spain). Formic acid, methanol and acetonitrile (OptimaTM LC-MS grade) were purchase from Fisher chemical (Loughborough, UK). Leucin Enkephalin was purchase from Waters Corporation (Milford, Massachusetts, USA). Ultrapure water was purified using a Milli-Q water purification system (Millipore, Billerica, MA, USA).

Instrumentation and experimental conditions. Chromatographic analysis was performed using a Waters Acquity UPLC ${ }^{\circledR}$ system (Waters Corporation, Milford, USA). Chromatographic separation was carried out at $40^{\circ} \mathrm{C}$, using a Waters ACQUITY HSS T3 $(100 \mathrm{~mm} \times 2.1 \mathrm{~mm}, 1.8 \mu \mathrm{m})$ column with mobile phases $\mathrm{A}(0.1 \%$ formic acid in water) and $\mathrm{B}(0.1 \%$ formic acid in absolute methanol). The flow rate was set at $0.4 \mathrm{~mL} / \mathrm{min}$. The gradient profile was as follows: $0-1 \mathrm{~min}, 0 \%-0 \% \mathrm{~B} ; 1-16 \mathrm{~min}, 0 \%-100 \% \mathrm{~B} ; 16-20 \mathrm{~min}$, $100 \%-100 \%$ B; 20-22 min, 100\%-0\% B; 22-24 min, 0\%-0\% B. Mass spectrometric detection was performed by Waters ${ }^{\circledR}$ SYNAPT G2-Si mass spectrometer (Waters Corporation, Milford, USA) with positive and negative ion detections with electrospray ionization (ESI) source for acquisition in MSE mode to investigate untargeted metabolomics analysis. The MSE mode set up as full scan mode which allowed both precursors and fragmentation data to be simultaneously acquired during a single run. This method 
consisted of three functions; low energy (LE) applied a collision energy of $4 \mathrm{eV}$, high energy (HE) acquired spectra through a ramp trap collision energy of 15-40 eV and the lock mass data for internal on-the-fly mass calibration. The MS mass range was set up at $50-1,200 \mathrm{~m} / \mathrm{z}$ with a scan time of 0.5 second in continuum mode, preserving the peak shape of the exact-mass precursor and product ions. The source conditions in resolution mode: capillary voltage $3 \mathrm{kV}$, sample cone $40 \mathrm{~V}$, source offset $80 \mathrm{~V}$, source temperature $150{ }^{\circ} \mathrm{C}$, desolvation temperature $500{ }^{\circ} \mathrm{C}$, cone gas flow rate $50 \mathrm{~L} / \mathrm{h}$, and desolvation gas (N2) flow rate at $1,000 \mathrm{~L} / \mathrm{h}$. During data acquisition, the mass to charge ratio $(\mathrm{m} / \mathrm{z})$ was $200 \mathrm{pg} / \mathrm{mL}$ solution of leucine enkephalin (Waters, USA) infused continuously at $5 \mu \mathrm{L} / \mathrm{min}$. via a lock spray interface. This generated were reference in positive mode at $\mathrm{m} / \mathrm{z} 556.2771[\mathrm{M}+\mathrm{H}]^{+}$and negative mode at $\mathrm{m} / \mathrm{z} 554.2615$ $[\mathrm{M}-\mathrm{H}]^{-}$to ensure mass accuracy and reproducibility.

Sample preparation. Sahatsatara formula (STF) powder was purchased from the Ayurved Siriraj Manufacturing Unit of Herbal Medicine and Products, Center of Applied Thai Traditional Medicine (CATTM), where controlled under the Pharmaceutical Inspection Cooperation Scheme the good manufacturing practice (PIC/S GMP) certification and all of the components authenticated by experienced Thai traditional practitioners (Faculty of Medicine, Siriraj Hospital, Mahidol University, Bangkok, Thailand). STF powder was extracted by ethanol $80 \%$ at ratio1:10 $(\mathrm{w} / \mathrm{v})$ by sonication 1 hour and filtration through GF/A filter paper particle filtration size of $1.6 \mu \mathrm{m}$ (Whatman, England), respectively. Then the solution was freeze-dried and stored in vacuum desiccator before use. The accurately weight STF powder extract $1 \mathrm{mg}$ was dispersed with absolute methanol $1 \mathrm{~mL}$ and mixed by vortex for $10 \mathrm{~min}$. Then, STF extracted solution was centrifuged at 12,000 rpm for $5 \mathrm{~min}$ at $4 \stackrel{\circ}{\circ} \mathrm{C}$ and serial dilution at $25,50,100 \mu \mathrm{g} / \mathrm{mL}$ with absolute methanol. The supernatant was filtered through $0.2 \mu \mathrm{m}$ polyvinylidene difluoride (PVDF) hydrophilic syringe filter. The final volume was $1 \mathrm{~mL}$ included internal standard solutions, then inject into an ultraperformance liquid chromatography coupled with quadrupole time-of-flight tandem mass spectrometry (UPLC-Q-TOF-MSE) system.

Method performance. Multivariate analysis (MVA) was performed by UNIFI software transfers the data to EZinfo software (Waters Corp., MA, USA). Multiple injections and samples were compared. This study also applied Principal Component Analysis (PCA) techniques which allowed the reduction of a large set of multivariate data into uncorrelated variables called principal components. Establishment of Untargeted Metabolite Profiling in STF. MassLynx ${ }^{\mathrm{TM}}$ V4.2 software was used to collect all data, MarkerLynx $\mathrm{X}^{\mathrm{TM}} \mathrm{XS}$ and MassFragment ${ }^{\mathrm{TM}}$ software and UNIFI software were applied for identifying chemical markers. The Traditional chinese medicine (TCM) library was performed in UNIFI software. It contains 6,399 compounds in both positive and negative modes. After matching with TCM library, the possible markers were found and need to elucidate for identification. The possible marker from UNIFI software was compared with literature review of compound identification of 21 herbal components of STF from several online databases searching including ChEBI (Chemical Entities of Biological Interest; https://www.ebi.ac.uk/chebi/), ChemSpider (http://www.chemspider.com/) and PubChem(https://pubchem.ncbi.nlm.nih.gov/) Data acquisition and processing was performed using UNIFI 1.8 screening platform on investigated untargeted (Waters, USA). UNIFI software is one of the most powerful tools for untargeted approach. It searched compounds to integrate data acquisition, data library for natural products and prefers to traditional Chinese medicine library for searching and predicting metabolite. The parameters were set as follows: retention time 0-24 min., Target match tolerance 10 ppm. High energy intensity threshold 1,000 counts, Low energy intensity threshold 50,000 counts, high noise background filter, TCMs 6,399 compounds and Adducts form were selected $\mathrm{H}+, \mathrm{Na}+, \mathrm{NH} 4+$ for positive ionization mode and $\mathrm{H}-, \mathrm{CHOO}-, \mathrm{CH} 3 \mathrm{COO}$ - for negative ionization mode. In addition, the workflow filters were set as follows: Retention time $0.5-20$ min., Mass error \pm 5 ppm. and Response $>50,000$ counts, respectively. 


\section{Results}

Metabolomic profiles and identification compounds of STF

In this study, The QCs pool was used to control reproducibility of metabolomics data before run the sample in both positive and negative ionization mode (Fig.1). The untargeted metabolic profiling was represented extracted base peak ion chromatogram (BPI) pattern of STF at concentration 25, 50 and 100 $\mu \mathrm{g} / \mathrm{mL}$. and identification compounds related with RT match TCMs library from UNIFI software in both modes (Supplementary Material, Fig.1-4). In addition, identification compounds of STF were represented 63 compounds in positive mode, 33 compounds in negative mode (Supplementary Material, Table 2-3) and total 21 identification compound were found in STF every concentration. There was literature review the chemical constituents which contains in each ingredient of STF (Table 1). Consequently, phytochemical group of 21 identified compounds were alkaloid and terpene $24 \%$ of each, fatty acid $19 \%$, steroids $10 \%$, polyphenols $9 \%$, and others. There are related with various pharmacological activities (Fig.2).

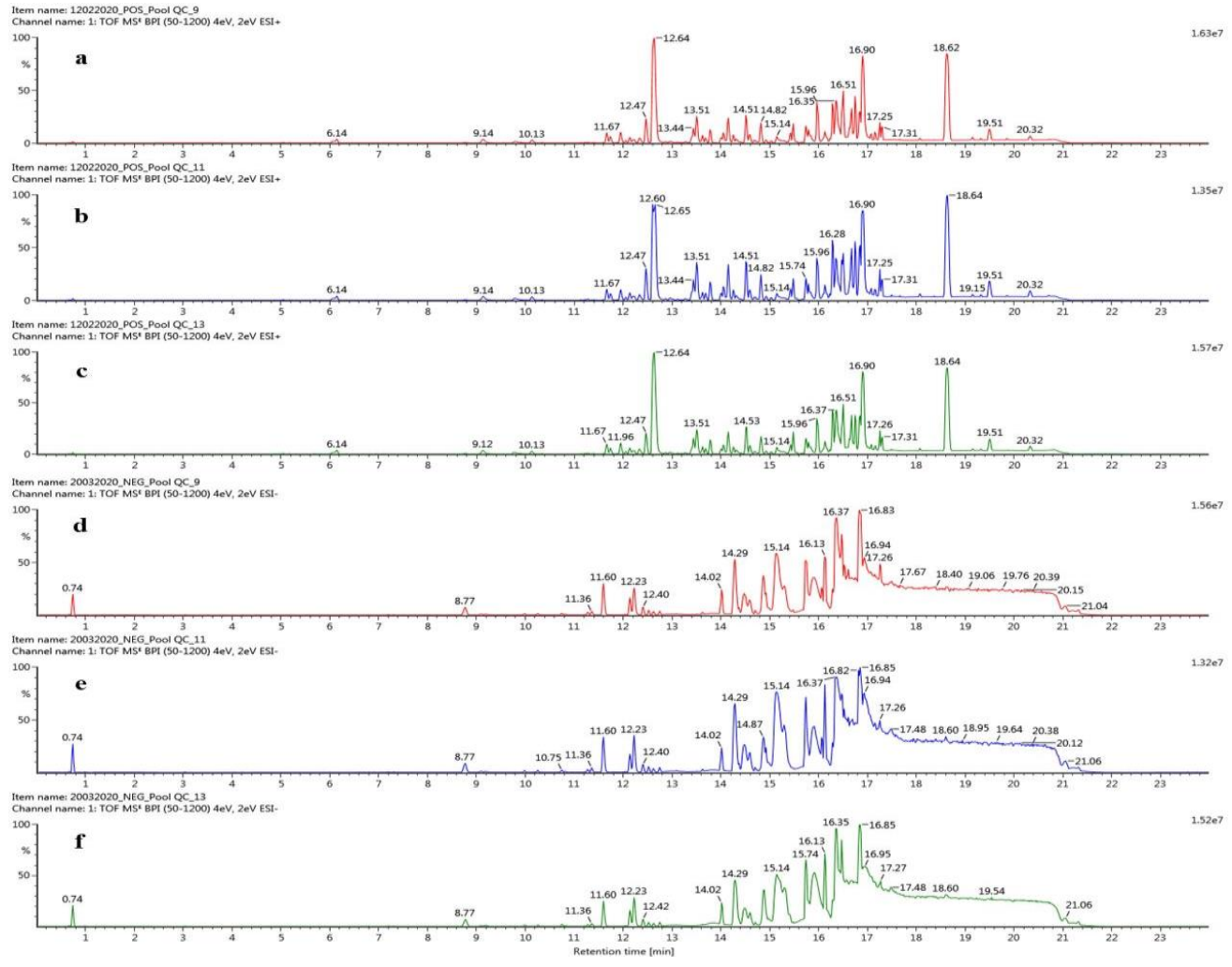

Figure.1 The base peak ion chromatograms of QCs pooled between injections with retention time and $\mathrm{m} / \mathrm{z}$ calculated to assess chromatographic stability; (a-c) positive ionization (d-f) negative ionization. Red, blue and green line referred to fragment ion characteristics of each QCs pooled injection which presented fragmentation pattern and consistency. 
Table 1 Identified compounds of STF and its components source.

\begin{tabular}{|c|c|c|c|c|c|c|c|c|}
\hline No. & $\begin{array}{c}\mathrm{RT} \\
\text { (min.) }\end{array}$ & Formula & Adduction & $\begin{array}{c}\text { Observed } \\
\text { mass }(\mathrm{m} / \mathrm{z})\end{array}$ & $\begin{array}{l}\text { Error } \\
(\mathrm{ppm})\end{array}$ & Identification & $\begin{array}{l}\text { Phytochemical } \\
\text { group }\end{array}$ & Source \\
\hline 1 & 0.74 & $\mathrm{C} 1 \mathrm{H} 22 \mathrm{O} 11$ & {$[\mathrm{M}+\mathrm{H}]^{+}$} & 208.1088 & -1.1 & $\beta$-Asarone & Disaccharides & $\begin{array}{c}\mathrm{AC}^{12-17} \\
\mathrm{MF} \\
\mathrm{LS}\end{array}$ \\
\hline 2 & 8.78 & $\mathrm{C} 14 \mathrm{H} 6 \mathrm{O} 8$ & {$[\mathrm{M}-\mathrm{H}]^{-}$} & 300.9987 & -0.8 & Ellagic acid & Polyphenols & $\begin{array}{c}\text { AG } \\
\text { PR } \\
\text { TC }^{18,19}\end{array}$ \\
\hline 3 & 11.96 & $\mathrm{C} 16 \mathrm{H} 17 \mathrm{NO} 3$ & {$[\mathrm{M}+\mathrm{H}]^{+}$} & 272.1274 & -2.6 & Piperyline & Alkaloids & $\mathrm{PN}^{20}$ \\
\hline 4 & 12.14 & $\mathrm{C} 16 \mathrm{H} 16 \mathrm{O} 3$ & {$[\mathrm{M}+\mathrm{NH} 4]^{+}$} & 274.1431 & -2.3 & Orchinol & Polyphenols & - \\
\hline 5 & 12.15 & $\mathrm{C} 30 \mathrm{H} 48 \mathrm{O} 6$ & {$[\mathrm{M}+\mathrm{Na}]^{+}$} & 527.3348 & 0.9 & Esculentagenic acid & Triterpenoids & - \\
\hline 6 & 12.48 & $\mathrm{C} 14 \mathrm{H} 16 \mathrm{~N} 2 \mathrm{O} 5$ & {$[\mathrm{M}+\mathrm{NH} 4]^{+}$} & 310.1405 & 2.6 & Astragaline $\mathrm{E}$ & Alkaloids & - \\
\hline 7 & 12.48 & $\mathrm{C} 17 \mathrm{H} 21 \mathrm{NO} 3$ & $\begin{array}{l}{[\mathrm{M}+\mathrm{H}]^{+}} \\
{[\mathrm{M}+\mathrm{Na}]^{+}}\end{array}$ & 288.1587 & -2.5 & Piperanine & Alkaloids & $\begin{array}{l}\mathrm{PN}^{21} \\
\mathrm{PR}^{21,22}\end{array}$ \\
\hline 8 & 12.64 & C17H19NO3 & $\begin{array}{c}{[\mathrm{M}+\mathrm{H}]^{+}} \\
{[\mathrm{M}+\mathrm{Na}]^{+}}\end{array}$ & 286.1431 & -2.4 & Piperine & Alkaloids & $\mathrm{PR}^{21,22,25}$ \\
\hline 9 & 13.63 & $\mathrm{C} 14 \mathrm{H} 22 \mathrm{O}$ & {$[\mathrm{M}+\mathrm{NH} 4]^{+}$} & 224.1998 & -4.9 & Longicamphenylone & Sesquiterpenoids & - \\
\hline 10 & 13.70 & $\mathrm{C} 19 \mathrm{H} 18 \mathrm{O} 3$ & {$[\mathrm{M}+\mathrm{NH} 4]^{+}$} & 312.1588 & -2.0 & Isotanshinone IIA & Quinonoids & - \\
\hline 11 & 13.79 & $\mathrm{C} 19 \mathrm{H} 22 \mathrm{O} 3$ & {$[\mathrm{M}+\mathrm{NH} 4]^{+}$} & 316.1904 & -1.2 & Ostruthin & Monoterpenoids & - \\
\hline 12 & 14.53 & C21H27NO3 & $\begin{array}{c}{[\mathrm{M}+\mathrm{H}]^{+}} \\
{[\mathrm{M}+\mathrm{Na}]^{+}}\end{array}$ & 342.2058 & -1.7 & Pipernonaline & Alkaloids & $\begin{array}{c}\mathrm{PN}^{23} \\
\mathrm{PR}^{21,25}\end{array}$ \\
\hline 13 & 15.81 & $\mathrm{C} 16 \mathrm{H} 26$ & $\begin{array}{c}{[\mathrm{M}+\mathrm{CH} 3 \mathrm{C}} \\
\mathrm{OO}]^{-}\end{array}$ & 277.2172 & -0.3 & Patchoulene & Monoterpenoids & - \\
\hline 14 & 16.16 & $\mathrm{C} 21 \mathrm{H} 40 \mathrm{O} 4$ & {$[\mathrm{M}+\mathrm{Na}]^{+}$} & 379.2814 & -1.2 & 2,3-Dihydroxypropyl oleate & Organic Esters & - \\
\hline 15 & 16.65 & $\mathrm{C} 22 \mathrm{H} 41 \mathrm{NO}$ & $\begin{array}{c}{[\mathrm{M}+\mathrm{H}]^{+}} \\
{[\mathrm{M}+\mathrm{Na}]^{+}}\end{array}$ & 358.3077 & -0.8 & $\begin{array}{l}\mathrm{N} \text {-Isobutyl-(2E,4E)- } \\
\text { octadecadienamide }\end{array}$ & Fatty acid & - \\
\hline 16 & 16.69 & $\mathrm{C} 2 \mathrm{OH} 34 \mathrm{O} 2$ & {$[\mathrm{M}+\mathrm{Na}]^{+}$} & 329.2447 & -1.1 & ent-Kauran-16 $\beta, 17$-diol & $\begin{array}{l}\text { Diterpenoids \& } \\
\text { Sesterterpenoids }\end{array}$ & - \\
\hline 17 & 16.85 & $\mathrm{C} 2 \mathrm{OH} 38 \mathrm{O}$ & {$[\mathrm{M}+\mathrm{NH} 4]^{+}$} & 312.3259 & -0.5 & 2-Eicosenal & Fatty acid & - \\
\hline 18 & 16.92 & $\mathrm{C} 18 \mathrm{H} 34$ & $\begin{array}{c}{[\mathrm{M}+\mathrm{CH} 3 \mathrm{C}} \\
\mathrm{OO}]^{-}\end{array}$ & 309.2800 & 0.4 & 9-Octadecyne & Fatty acid & - \\
\hline 19 & 16.95 & $\mathrm{C} 2 \mathrm{OH} 36 \mathrm{O} 2$ & {$[\mathrm{M}+\mathrm{Na}]^{+}$} & 331.2600 & -2.2 & Ethyl linoleate & Fatty acid & - \\
\hline 20 & 17.41 & $\mathrm{C} 36 \mathrm{H} 62 \mathrm{O} 8$ & {$[\mathrm{M}-\mathrm{H}]^{-}$} & 621.4365 & -1.1 & Ginsenoside Rh2 & $\begin{array}{l}\text { Steroidal } \\
\text { glycosides }\end{array}$ & - \\
\hline 21 & 17.41 & $\mathrm{C} 35 \mathrm{H} 60 \mathrm{O} 6$ & {$[\mathrm{M}+\mathrm{Na}]^{+}$} & 599.4293 & 1.8 & $\beta$-Daucosterol (Daucosterol) & Steroid saponin & - \\
\hline
\end{tabular}

STF components; AC (Acorus calamus L.), TC (Terminalia chebula Retz.), PN (Piper nigrum L.), MF (Myristica fragrans Houtt. [Fruits]), LS (Lepidium sativum L.), AG (Anethum graveolens L.), PR (Piper retrofractum Vahl).

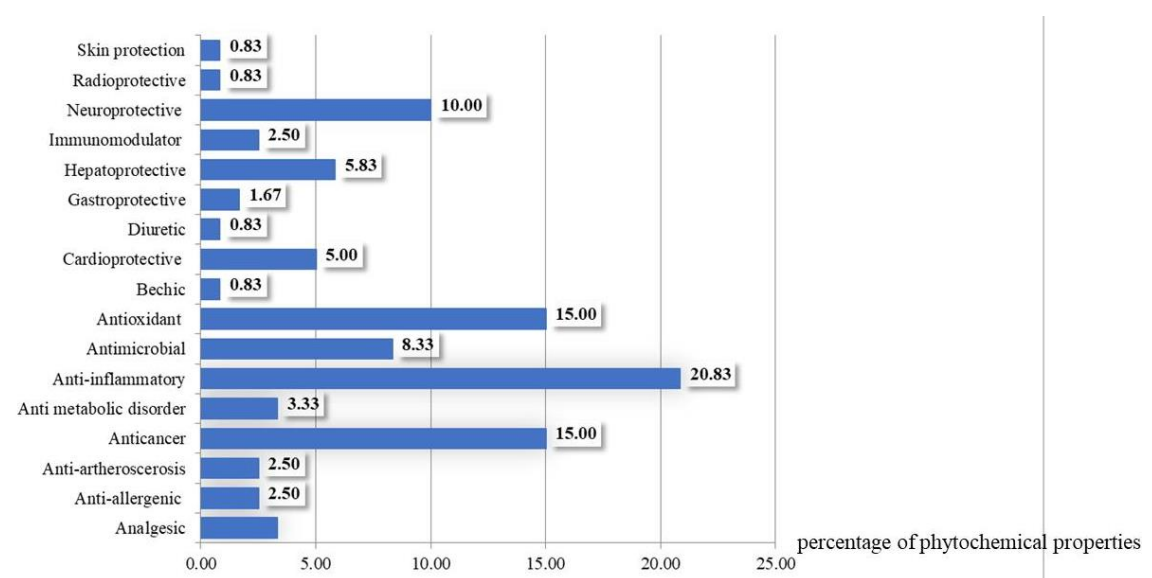

Figure.2 The bar chart was represented percentage of pharmacological activities of STF extracts

\section{Discrimination of STF metabolic compounds using multivariate data analysis}

Principle Component Analysis (PCA) is an efficient unsupervised clustering tool to observe the clustering trends between individual samples for finding the similarities or differences among standard mixture and 
STF samples in any concentration. The PCA scores plot showed the standard mixture group and processed STF extracts concentrations at $25,50,100 \mu \mathrm{g} / \mathrm{mL}$. The results demonstrated that STF extracts and standard mixture were distinctly separated to the four clusters in both ionizations (Fig.3). The standard mixture cluster was located in the one-quadrant and the processed STF extracts sample on the other quadrants. The numbers of sample injections were described as follows: standard mixture $(n=5)$, STF extracts 25 $\mu \mathrm{g} / \mathrm{mL}(\mathrm{n}=5)$, STF extracts $50 \mu \mathrm{g} / \mathrm{mL}(\mathrm{n}=5)$, and STF extracts $100 \mu \mathrm{g} / \mathrm{mL}(\mathrm{n}=5)$.

In multivariate statistical analysis of STF extracts, a total of 557 variables (positive mode) and 313 variables (negative mode) were analysed. The PCA scores plots of data were shown in Figure 5.14 which provided $R 2 X[1]=0.6508$ and $R 2 X[2]=0.2434$ in positive mode and $R 2 X[1]=0.3811$ and $R 2 X[2]=0.1277$ in negative mode. These parameters suggested the model performed a relatively more excellent prediction in positive mode than negative mode.
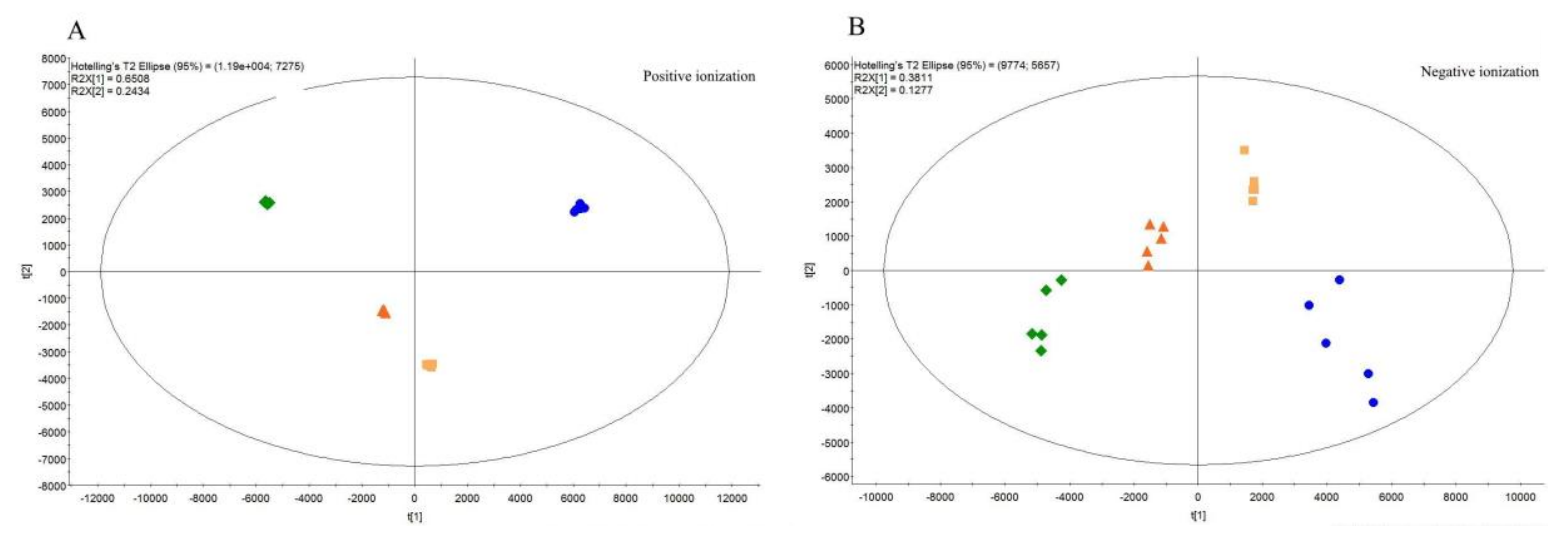

Figure. 3 Principle component analysis scores plot (PCA) for classifying standard group and STF concentration at $25,50,100 \mu \mathrm{g} / \mathrm{mL}$ group in negative mode. The results revealed that all of STF extracts and standard mixtures were obviously separated. (A) positive ionization ; (B) negative ionization.

Noted : plumbagin and piperine standard mixtures at $10 \mu \mathrm{g} / \mathrm{mL}$; : STF concentration at $25 \mu \mathrm{g} / \mathrm{mL}$; : STF concentration at $50 \mu \mathrm{g} / \mathrm{mL} ;$ : STF concentration at $100 \mu \mathrm{g} / \mathrm{mL}$

\section{Chemical profile markers of six major STF components}

21 identified compounds were review identification compounds of STF components from previous study. The six major ingredients of STF were Piper nigrum L. (PN); piperine, piperanine, piperyline and pipernonaline, Plumbago indica L. (PI), Piper retrofractum Vahl (PR); piperine, piperanine and pipernonaline, Terminalia chebula Retz. [Fruit] (TC); ellagic acid, Acorus calamus L. (AC); $\beta$-asarone and Baliospermum solanifolium (Burm.) Suresh. (BS) (Fig.4). They combined together more than $80 \%$ of total weights. The results from UNIFI software were confirmed by mass spectra of identifications compound and chemical structure from ChEBI and Chemspider online database (Supplementary Material, Fig.5-10). Moreover, the quality in the metabolomics data was calculate \%RSD (Relative standard deviation) to assure repeatable procedures in this experiment. The RSD possible to calculate on the area of each identification compound obtained in five injections. The RSD values $(X)$ were classified into three categories: $0<X \leq 10 \%, 10<X \leq 20 \%$, or $20<X \leq 30 \%$. The RSD of most identification compounds was less than $10 \%$ and not over than $30 \%$. 


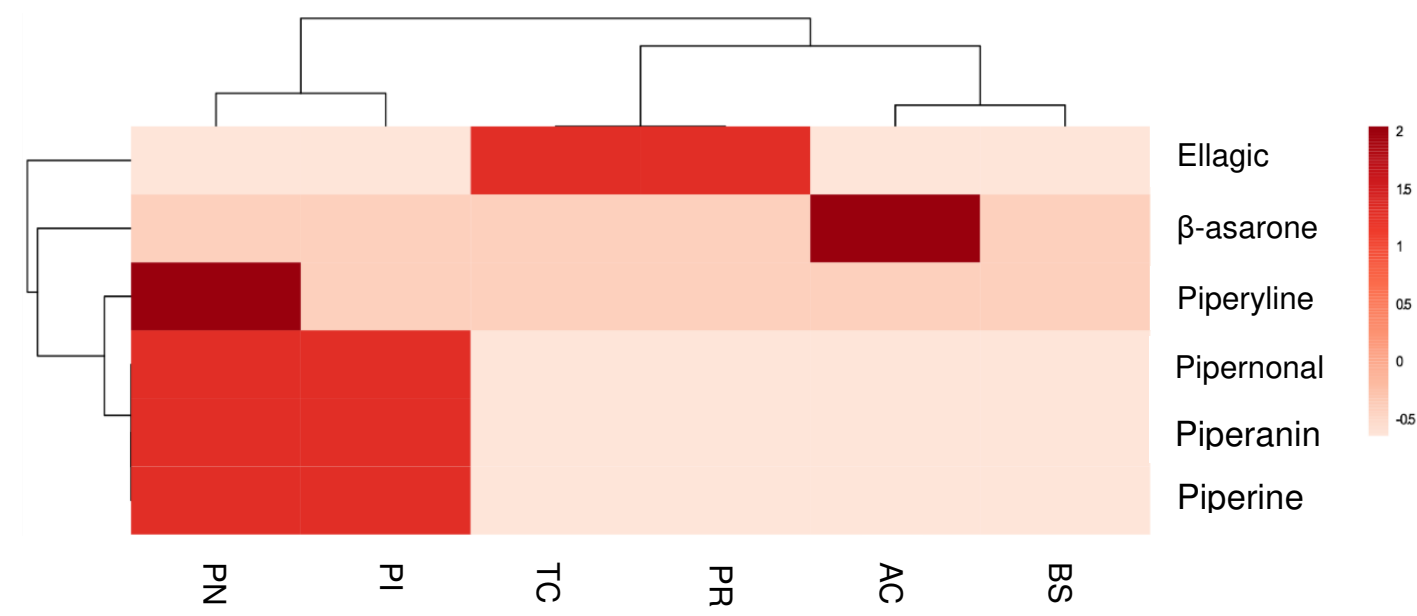

Figure. 4 Hierarchical clustering of the heatmap of identification compounds in TCM library were presented in six major STF components from previous studied. The heatmap scale ranges from -0.5 to 2 on a log2 scale with the dendrogram being scaled to represent the distance between each branch (distance measure: Pearson's correlation). The clusters containing $\beta$-asarone and Piperyline are highlighted dark red represented in Piper nigrum L. and Acorus calamus L., respectively.

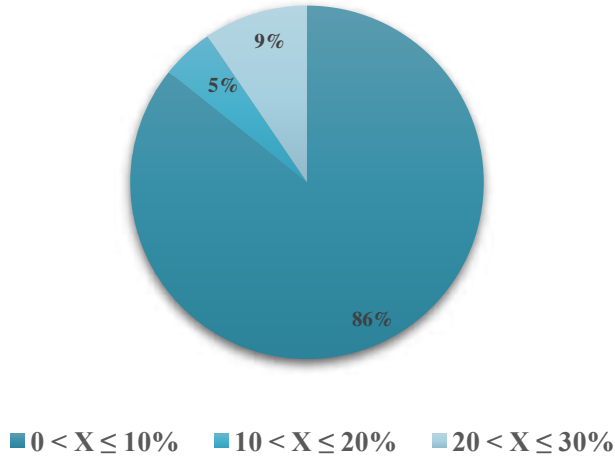

Figure. 5 Relative standard deviation (RSD) values calculated on the area each injections identification compound for the five injections. RSD (X) are classified into 3 categories: $0<X \leq 10 \%, 10<X \leq 20 \%$ or $20<$ $x \leq 30 \%$

\section{Discussion}

In this study, for controlling study preventing experimental bias were three stages of control including the pre-analytical; kept in a protective which controls temperature and humidity, the analytical; created worklist, observe internal standard (caffeine-C13, Cholic-[2H4]), external standard (piperine and plumbagin); There was the main metabolomics marker of two major components of STF which found in Piper nigrum L. $24 \%$ and Plumbago indica L. $22.4 \%$ from the total weight of STF. Hence, only piperine was represented with high abundance at specific retention time in positive mode ${ }^{4,7,26,27}$, lock mass calibration ${ }^{28}$, replicated pooled QCs, randomization and spike sample. Finally, the post-analytical; there was setting filtration parameters to matching with TCMs library. Although, quantification was not presented in this study. Hence, this study preferred to used untargeted metabolomics screening by matching and identification compound by used TCMs library ${ }^{29}$. Further study suggests quantify in targeted study. 
Interesting, we are the first who used the PCA for classifying in STF. This technique can predict the chemical compounds of STF was difference. The standard mixture group and STF extracts concentration at $25,50,100 \mu \mathrm{g} / \mathrm{mL}$ group in the positive mode were shown more dramatically separated than the negative mode. The standard mixture group was separated in one quadrant apart from STF extracts group. Moreover, STF three concentrations were separated but STF extracts concentration at 25 and $50 \mu \mathrm{g} / \mathrm{mL}$. still closely than $100 \mu \mathrm{g} / \mathrm{mL}$.

The results were not presented plumbagin in our condition even if plumbagin was a principle component of Plumbago indica L.. In addition, Plumbago indica L. was contained in STF $22.4 \%$ which in secondary ingredients in the formula. we cannot assume that the major constituent in the formula should be selected as a biomarker. Nevertheless, there are many external factors that can affect to metabolomics profiles data such as quality of raw materials and part of usage. There was primary concern for HMs quality control since environment growth until appropriate time to harvest. In addition, processing parameters in UNIFI software were used in this study was limited mass error, retention time and response in a narrow range that cannot include some compound was low intensity and higher mass error in our results. Other study used widely range of response $\geq 200$ counts which represented numerous compounds ${ }^{29}$.

STF extracts concentration at 25,50 and $100 \mu \mathrm{g} / \mathrm{mL}$ were matching with TCMs library which represented similarity and difference identified compounds. The similarity of STF three concentrations was represented. There were consisted of 16 and 5 identified compounds for positive ionization and negative ionization, respectively (Supplementary Material, Table.2-3). The concentration of the sample is an essential factor that impacts for untargeted metabolomics profiles data ${ }^{30}$. The identified compounds of STF concentration at 25 and $50 \mu \mathrm{g} / \mathrm{mL}$ also found in STF at $100 \mu \mathrm{g} / \mathrm{mL}$. Moreover, there were only 21 identified compounds that found all three STF concentration (Table 1). Thus, our results suggested that 21 identified compounds can be used for further targeted metabolomics investigation study. Moreover, 21 identified compounds from STF three concentrations also included piperine which similar as previous study $^{4,7,27}$.Piperine has been used for targeted metabolic profiles marker of STF. Hence, other 20 compounds in this study were firstly reported as novel identified compounds of STF.

The most of classification phytochemical in STF was alkaloids including piperyline, astragaline $E$, piperanine, piperine, pipernonaline. Previous studies demonstrated that there are several pharmacological effects such as anti-inflammatory, antioxidant, anti-mutagenic, anti-cancer effects, antidepressant-like effects, anti-diarrheal properties, protective to gastric ulcer, antifungal activity, and anti-analges ${ }^{31,32}$. Secondly, phytochemical group was terpenes including monoterpenoid; ostruthin, patchoulene. diterpenoids and sesterterpenoids; ent-Kauran-16ß,17-diol, longicamphenylone. triterpeniods; esculentagenic acid. The pharmacological effects were antifungal activity, antibacterial activity, anti-inflammation ${ }^{33-35}$. Thirdly, phytochemical group was fatty acid including N-Isobutyl-(2E,4E)octadecadienamide, 2-eicosenal, 9-octadecyne. Pharmacological effects were gastro-protective effect ${ }^{36}$. The pharmacological effects of alkaloid and terpene classifications were related to traditionally used as agent. Moreover, other classification consists of disaccharide ( $\beta$-asarone). $\beta$ - asarone was found in Acorus calamus L. Pharmacological effect was shown antidepressant, antianxiety, anti-Alzheimer's, antioxidant, anti-inflammation ${ }^{37,38}$. Polyphenols group consist of ellagic acid, orchinol as identified compounds. Pharmacological effect was shown anti-inflammation and analgesic ${ }^{39}$. Quinoloid derivatives was identified as Isotanshinone II A. this compound was not found in literature review chemical compound of STF ingredients. there was shown in Chinese herbal medicine and used as remove blood stasis. Pharmacological effect of phytochemical group was shown anti-inflammation ${ }^{40}$. Organic esters group was identified as dihydroxypropyl oleate. Pharmacological effect of phytochemical group was shown antiinflammation and Steroids group, ginsenoside Rh2 and $\beta$-Daucosterol were presented. The pharmacological effect was the pain relief ${ }^{41}$. Most of phytochemical propertied of identified compound of STF was related to traditional usage including anti-inflammatory, antioxidant, analgesic. 


\section{Conclusion}

This study established untargeted metabolomics methods including positive and negative modes to identified numerous chemical compounds of STF and compare with Traditional Chinese medicine (TCM) library by using UNIFI software. These conditions were highly sensitivity and reproducibility for STF chemical profile identification. There were several lock spray reference and internal standards, including Leucine enkephalin, Caffeine-C13 and Cholic-[2H4] and pooled QCs sample for confirmation of reliable condition performance. Regarding to PCA and the base peak ion chromatograms of STF and pooled QCs revealed that positive ionization performed high potentials for chemical separation and identification. Moreover, this research was firstly discovered new chemical markers of STF using untargeted metabolomic approach and multivariate analysis. Additionally, we found that not only piperine is a marker-controlled in STF but also twenty chemical compositions in STF were alkaloids (piperyline ,astragaline E, piperanine, pipernonaline), terpenes (longicamphenylone, ostruthin, patchoulene, ent-Kauran16ß,17-diol, esculentagenic acid), fatty acids (N-Isobutyl-(2E,4E)-octadecadienamide, 2eicosenal, 9-octadecyne, ethyl linoleate), polyphenols (ellagic acid, orchinol), steroidal glycosides (ginsenoside Rh2), steroid saponins ( $\beta$-daucosterol), organic esters ( $\mathrm{N}$-lsobutyl-(2E,4E)octadecadienamide), disaccharides ( $\beta$ - asarone) and quinonoids (Isotanshinone II A).

\section{References}

1 Enioutina, E. Y. et al. Herbal Medicines: challenges in the modern world. Part 5. status and current directions of complementary and alternative herbal medicine worldwide. Expert review of clinical pharmacology 10, 327-338 (2017).

2 Wechwithan, S. et al. Signal detection for Thai traditional medicine: examination of national pharmacovigilance data using reporting odds ratio and reported population attributable risk. Regulatory Toxicology and Pharmacology 70, 407-412 (2014).

3 Chokevivat, V. \& Chuthaputti, A. in Proceedings of the 6th Global Conference on Health Promotion. 7-11 (Citeseer).

4 Booranasubkajorn, S. et al. Vasculoprotective and vasodilatation effects of herbal formula (Sahatsatara) and piperine in spontaneously hypertensive rats. Phytomedicine 24, 148-156 (2017).

5 Qi, Z. \& Kelley, E. The WHO traditional medicine strategy 2014-2023: a perspective. Science 346, S5-S6 (2014).

$6 \mathrm{Li}, \mathrm{S}$. et al. Chemical markers for the quality control of herbal medicines: an overview. Chinese medicine 3, 1-16 (2008).

7 Thamsermsang, O., Akarasereenont, P., Laohapand, T. \& Panich, U. IL-1 $\beta$-induced modulation of gene expression profile in human dermal fibroblasts: the effects of Thai herbal Sahatsatara formula, piperine and gallic acid possessing antioxidant properties. $B M C$ complementary and alternative medicine 17, 1-13 (2017).

8 Shyur, L. F., Liu, C. P. \& Chien, S. C. Metabolomics in herbal medicine research. The Handbook of Plant Metabolomics, 155-174 (2013).

9 Zhang, H.-M. et al. Holistic quality evaluation of commercial white and red ginseng using a UPLC-QTOF-MS/MS-based metabolomics approach. Journal of pharmaceutical and biomedical analysis 62, 258-273 (2012).

10 Tautenhahn, R. et al. An accelerated workflow for untargeted metabolomics using the METLIN database. Nature biotechnology 30, 826-828 (2012). 
11 Commisso, M., Strazzer, P., Toffali, K., Stocchero, M. \& Guzzo, F. Untargeted metabolomics: an emerging approach to determine the composition of herbal products. Computational and structural biotechnology journal 4, e201301007 (2013).

12 Bhattarai, S., Gautam, M. \& Tamang, R. Comparative study of active constituents of some medicinal plants along altitudinal gradient.

13 Rajput, S. B., Tonge, M. B. \& Karuppayil, S. M. An overview on traditional uses and pharmacological profile of Acorus calamus Linn.(Sweet flag) and other Acorus species. Phytomedicine 21, 268-276 (2014).

14 El-Salam, A., Kholoud, H., Toliba, A., El-Shourbagy, G. A. \& El-Nemr, S. E. Chemical and functional properties of garden cress (Lepidium sativum L.) seeds powder. Zagazig Journal of Agricultural Research 46, 1517-1528 (2019).

15 Odubanjo, V. O., Olasehinde, T. A., Oyeleye, S. I., Oboh, G. \& Boligon, A. A. Seed extracts from Myristica fragrans (Nutmeg) and Moringa oleifera (Drumstick tree) inhibits enzymes relevant to erectile dysfunction and metal-induced oxidative damage in rats' penile tissues. Journal of Food Biochemistry 42, e12452 (2018).

16 Violeta, N., Trandafir, I. \& Cosmulescu, S. Bioactive compounds, antioxidant activity and nutritional quality of different culinary aromatic herbs. Notulae Botanicae Horti Agrobotanici Cluj-Napoca 45, 179-184 (2017).

17 Yun, J., Kim, C., Kim, M.-B. \& Hwang, J.-K. Piper retrofractum Vahl. extract, as a PPARס and AMPK activator, suppresses UVB-Induced photoaging through mitochondrial biogenesis and MMPs inhibition in human dermal fibroblasts and hairless mice. Evidence-Based Complementary and Alternative Medicine 2018 (2018).

18 Kumar, N. \& SM, P. K. Phytochemistry and Medicinal Value of Harad (Terminalia chebula Retz.) the 'King of Medicinal Plants'.

19 Sarabhai, S., Sharma, P. \& Capalash, N. Ellagic acid derivatives from Terminalia chebula Retz. downregulate the expression of quorum sensing genes to attenuate Pseudomonas aeruginosa PAO1 virulence. PLoS one 8, e53441 (2013).

20 de Souza Grinevicius, V. M. A. et al. Piper nigrum ethanolic extract rich in piperamides causes ROS overproduction, oxidative damage in DNA leading to cell cycle arrest and apoptosis in cancer cells. Journal of ethnopharmacology 189, 139-147 (2016).

21 Liu, H.-L. et al. Identification and simultaneous quantification of five alkaloids in Piper longum L. by HPLC-ESI-MSn and UFLC-ESI-MS/MS and their application to Piper nigrum L. Food chemistry 177, 191-196 (2015).

22 Wiwattanawanichakun, P. et al. The possibility of using isolated alkaloid compounds and crude extracts of Piper retrofractum (Piperaceae) as larvicidal control agents for Culex quinquefasciatus (Diptera: Culicidae) larvae. Journal of medical entomology 55, 1231 1236 (2018).

23 Buranrat, B. \& Boontha, S. Effect of Piper nigrum ethanolic extract on human breast cancer cell growth and cell migration. Pharmacognosy Magazine 15, 538 (2019).

24 Kolhe, S. R., Borole, P. \& Patel, U. Extraction and evaluation of piperine from Piper nigrum Linn. International Journal of Applied Biology and Pharmaceutical Technology 2 , 144-149 (2011).

25 Tang, R. et al. New amides and phenylpropanoid glucosides from the fruits of Piper retrofractum. Natural products and bioprospecting 9, 231-241 (2019).

26 Nuengchamnong, N. \& Ingkaninan, K. An on-line LC-MS/DPPH approach towards the quality control of antioxidative ingredients in Sahastara. Songklanakarin Journal of Science \& Technology 39 (2017).

$27 \mathrm{P}, \mathrm{K}$. The clinical safety and pharmacokinetics of SAHASTARA remedy ethanolic extract capsules in healthy vulunteers (Clinical Trial Phase 1), THAMMASAT UNIVERSITY, (2017). 
28 Arapitsas, P. \& Mattivi, F. LC-MS Untargeted Protocol for the Analysis of Wine. Methods in molecular biology (Clifton, NJ) 1738, 225-235 (2018).

29 Zhang, F.-x. et al. Rapid characterization of Ziziphi Spinosae Semen by UPLC/Qtof MS with novel informatics platform and its application in evaluation of two seeds from Ziziphus species. Journal of pharmaceutical and biomedical analysis 122, 59-80 (2016).

30 Caesar, L. K., Kellogg, J. J., Kvalheim, O. M. \& Cech, N. B. Opportunities and limitations for untargeted mass spectrometry metabolomics to identify biologically active constituents in complex natural product mixtures. Journal of natural products 82, 469484 (2019).

31 Durant-Archibold, A. A., Santana, A. I. \& Gupta, M. P. Ethnomedical uses and pharmacological activities of most prevalent species of genus Piper in Panama: A review. Journal of ethnopharmacology 217, 63-82 (2018).

32 Mehmood, M. H. \& Gilani, A. H. Pharmacological basis for the medicinal use of black pepper and piperine in gastrointestinal disorders. Journal of medicinal food 13, 10861096 (2010).

33 Joa, H. et al. Identification of ostruthin from Peucedanum ostruthium rhizomes as an inhibitor of vascular smooth muscle cell proliferation. Journal of natural products $\mathbf{7 4}$, 1513-1516 (2011).

34 Qin, G.-W. Some progress on chemical studies of triterpenoid saponins from Chinese medicinal plants. Curr. Org. Chem 2, 613-625 (1998).

35 Zhang, Z. et al. Anti-inflammatory activity of $\beta$-patchoulene isolated from patchouli oil in mice. European Journal of Pharmacology 781, 229-238 (2016).

36 Islam, M. T. et al. Chemical profile, traditional uses, and biological activities of Piper chaba Hunter: A review. Journal of ethnopharmacology 257, 112853 (2020).

37 Chang, W. \& Teng, J. $\beta$-asarone prevents $A \beta 25-35$-induced inflammatory responses and autophagy in SH-SY5Y cells: Down expression Beclin-1, LC3B and up expression Bcl-2. International Journal of Clinical and Experimental Medicine 8, 20658 (2015).

38 Chellian, R., Pandy, V. \& Mohamed, Z. Pharmacology and toxicology of $\alpha$-and $\beta$ Asarone: A review of preclinical evidence. Phytomedicine 32, 41-58 (2017).

39 Mo, J., Panichayupakaranant, P., Kaewnopparat, N., Nitiruangjaras, A. \& Reanmongkol, W. Topical anti-inflammatory and analgesic activities of standardized pomegranate rind extract in comparison with its marker compound ellagic acid in vivo. Journal of ethnopharmacology 148, 901-908 (2013).

40 Ferreira, V. F. et al. Structural evaluation of three 2-phenylpyrazolo [4, 3-c] quinolin-3one monohydrates. Journal of Molecular Structure 1051, 299-309 (2013).

41 Vyvey, M. Steroids as pain relief adjuvants. Canadian Family Physician 56, 1295-1297 (2010).

\section{Acknowledgements}

The herbal ingredients, chemical materials, experimental instrument were supported by Center of Applied Thai Traditional Medicine and the Department of pharmacology, Faculty of Medicine Siriraj Hospital, Mahidol University, Thailand. And the authors are grateful to Miss Jantanee Wattanarangsan from Department of pharmacology and Dr. Onusa Thamsermsang for LC-MS analysis and suggestions. This work was financially supported by by Siriraj Research and Development Fund (Grant No. R016132028) and the Chalermphrakiat Grant, Faculty of Medicine Siriraj Hospital, Mahidol University, Thailand. Moreover, helpdesk transfer manuscripts by Metabolomics journal (MEBO). All the authors express their deep thanks. 


\section{Author contributions}

P.A., M.V. and N.Z conceived and designed the experiments, M.V. and N.Z performed the experiments, and analyzed the data. All authors reviewed the manuscript.

\section{Competing interests}

The authors declare that they have no competing interests. 


\section{Supplementary Files}

This is a list of supplementary files associated with this preprint. Click to download.

- Supplymentarymaterial4.pdf

- Supplymentarymaterial4.pdf 